\title{
A Multi-Grounded Design Research Process
}

\author{
Göran Goldkuhl ${ }^{1,2}$ and Mikael Lind ${ }^{3,4}$ \\ ${ }^{1}$ Linköping University, Dep. of Management and Engineering, Sweden \\ Goran. Goldkuhleliu.se \\ ${ }^{2}$ Stockholm University, Dep. of Computer \& Systems Sciences, Sweden \\ ${ }^{3}$ Viktoria institute, Sweden \\ Mikael.Lind@viktoria.se \\ ${ }^{4}$ University of Borås, School of Business \& Informatics, Sweden
}

\begin{abstract}
There has been a growing interest in the philosophy and constituents of design research by a vast amount of IS-scholars. There are several unresolved concerns and issues in design research (DR). Some examples are the outcomes of design research, the role of theorizing in DR, how to conduct evaluation and validation, and the need for different grounding processes to generate valid knowledge from design research endeavors. This paper describes a multi-grounded approach for design research; consisting of three types of grounding processes (theoretical, empirical and internal grounding). The purpose is to investigate DR-based design knowledge and its roles during design research and design practice. A key feature in this approach is the division between the meta-design (within design research) producing abstract design knowledge and the empirical design practice producing situational knowledge and artefacts. The multi-grounding approach to design research will be illustrated by the support of two design cases.
\end{abstract}

Keywords: Design research, multi-grounded knowledge development.

\section{Introduction}

\subsection{Background: Important Concerns in Design Research Evolution}

There is an increasing interest for design research (DR) within the information systems (IS) community. One might add, a growing interest for the explicit notion of design research (or design science). Actually, there has been a great interest for design oriented research within IS for long time, although it did not had that specific label earlier; cf. e.g. the seminal paper by Nunamaker et al [27] who use the term "systems development research". There have during the IS research history been many research endeavours comprising the design and construction of information systems. Of course, the introduction of concepts like design theory [36] and design science [23] have put a lot of focus and emphasis on design research as an acceptable and viable research approach in IS.

There are several pending issues within DR [7, 19, 35, 37]: What outcomes are there from DR? What is the role of theory and theorizing in DR? What is the relation between design research and design practice? What is included in DR and what is 
not? What relations are there between DR and other research approaches like e.g. action research? How should evaluation and validation be conducted in DR?

There are different views on the outcome from DR. March \& Smith [23] and Hevner et al [18] describe four typical outcomes: constructs, models, methods, and instantiations which are all seen as artefacts. We understand artefacts as "things", i.e. entities that have some separate existence. Hevner et al [18, pp. 82] explicitly exclude "people" and "processes" from artefacts (as outcomes from IS design research). Constructs are defined as "concepts" and "conceptualizations" [23, pp. 256] and "vocabulary and symbols" [18, pp. 77]. When exemplifying constructs, March \& Smith [23, pp. 256] mention "relational data model" and "software incremental development". It is obvious from their examples and reasoning that constructs are abstracted concepts aimed for theorizing and trans-situational use. "Conceptualizations are extremely important in both natural and design science. They define the terms used when describing and thinking about tasks" [23, pp. 256]. Models are not conceived as abstract entities in the same way as constructs. "Models use constructs to represent a real world situation - the design problem and its solution space..." "Models aid problem and solution understanding and frequently represent the connection between problem and solution components enabling exploration of the effects of design decisions and changes in the real world." [18, pp. 78-79]. Models are thus defined as situational representations. When we move to methods (as a DR outcome), we have jump to a more abstract level again. A method is defined as "a set of steps (an algorithm or guideline) to perform a task" [23, pp. 257]. The authors exemplify with systems development methods, which makes it obvious that this is a general and abstracted artefact and not a situational. An instantiation is a prototype or a specific working system or some kind of tool. This is obviously a situational result. These different results may relate to design process or design product, which is in line with [36].

We find it conceptually problematic that these four different outcomes/artefacts vary between abstracted vs. situational result. March \& Smith [23] and Hevner et al [18] are reluctant to bring in theories into design research. They keep them aside in a "natural science" domain and in the supporting "knowledge base". However parts of theories creep into design research outcomes through constructs and methods. These are seen as important elements of design theories and partially of kernel theories by other scholars $[15,35,36]$.

What kind of knowledge results emerge through design research and how should they be seen in an abstract vs. situational dichotomy? This is one important research issue that we will address in this paper. There are however some more questions related this emphasised issue. One important issue is how to conceive design practice in relation to design research. In many descriptions, it is obvious that design practice is a part of design research and also considered as the key part. If so, what distinguishes normal design practice from design practice integrated into design research? This question will be necessary for us to discuss later in the paper. This involves also a clarification of relations between the design practice in DR and other activities in DR of more genuinely scientific character. The issue of interaction between design and theorizing has been addressed by several scholars [15, 19, 35, 36]. In the context of our reasoning we need to say something more about this. Design theory seems to play an important role in design research. 
One core issue in making a design task a research endeavour is how the design is studied and evaluated. The design research literature consists of several suggestions how this can be done [18, 28]. From these examples a pluralistic view emerges. Evaluation and validation of results can be conducted in many different ways. Once again, the relations to theorizing appear to be essential. Hevner [17] describes the interaction between design research and the existing knowledge base as a "rigor cycle" consisting of "grounding" [17, pp. 88]. We agree that such type of grounding should be performed, but we claim that it is too restricted to limit grounding to the relations with existing knowledge base. There are more grounding activities to be conducted within DR. We will address this issue in more depth in the following. What kinds of different grounding activities should be performed within a DR endeavour?

Some authors describe evaluations to be performed through the conduct of case studies $[18,28]$. This is however not a well-addressed issue within DR/IS. It is a bit astonishing actually that the case notion is not treated in-depth in the DR literature. We think that design research is always working with design-cases. The design of a specific IT artefact is a design-case and this makes this kind of research usually a one case research. But there may be research inquiries studying and evaluating several situations where a designed artefact is used. So, there is an important research design issue whether there should be a single design-case or a multiple design-case approach?

Broad surveys on the use of designed IT artefacts are usually not considered as design research. This means that design theorizing rather emanates from one or a limited number of design cases. In this respect it resembles grounded theory (GT) oriented research [34]. If so, what are the relations between design theorizing and GT theorizing? What are the resemblances and differences?

In classical GT there is an emphasis on building theory from data. GT comprises theory discovery through induction rather than a theory-testing approach. In a design situation (involving DR), there will usually be an active use of design knowledge (design theories or models) that should inform the design process. Contrary to GT, in design research there is an emphasis on hypothesis-testing [15, 36]. This implies that GT should not be used in a classical way in design research. If GT should be used at all, it needs to be adapted to the design frame.

Grounded theory has been used in change oriented research; cf. e.g. "Grounded Action Research" [6] and "Grounded Action" [31]. These approaches have been developed in combination with action research and not explicitly within a design research frame.

Multi-grounding in design theorizing $[12,21]$ is one approach with partial inspiration from grounded theory. In traditional grounded theory there is a focus on grounding the theory in data; which should be done by explicitly building the theory on data. Multi-grounding comprises empirical grounding but adds also theoretical and internal grounding. These three grounding processes should be used in a continual and iterative way through the emergence of a design theory. Grounding implies both informed generation and validation through proving.

\subsection{Purpose and Research Approach}

The purpose of this paper is to investigate DR-based design knowledge and its roles during design research and design practice. This implies also that we need to clarify 
how design practice is related to design research. In our inquiry into design knowledge we will especially look into the notion of multi-grounding as a possible approach to design research. We will discuss different types of design knowledge and how these are related to different grounding processes. We will not so much dig into the notion of design theory since there are several recent contributions here [15, 19, 35]. We find it more urgent to clarify design knowledge in terms of abstracted vs. situational knowledge.

Our research approach for clarifying and developing this multi-grounded design research (MGDR) will in itself be a case of design research. It will be a combination of conceptual and empirically oriented design endeavours. Two empirical cases will be used for illustration and partial validation. MGDR has emerged through a number of DR cases and we delimit our presentation here to two cases. MGDR should be seen as a pragmatic research approach following the spirit of Dewey's [10] pragmatic inquiry. In this pragmatic perspective, the world is always in a state of becoming and knowledge is thus provisional and always evolving and evolvable. Validation and grounding is always partial. Our knowledge evolves over time through continual cycles of generation, usage, evaluation and revision.

In our introduction above we have clarified some knowledge needs in design research that justify the purpose of this paper. In the next section we will elaborate on different types of design knowledge and outcomes from DR as well as the role of design practice within DR. Some aspects of the multi-grounded approach will be presented in section 3. In section 4 we will give an overview of two design cases. The MGDR approach will be articulated in section 5 and the paper is concluded in section 6 .

\section{Design Practices and Design Knowledge}

One way to understand design research (as research) is to understand the outcomes from this kind of activity. However, following Hevner et al [18] it remains unclear what really are the scientific results from design research. They describe it in the following way: "The result of design-science research in IS is, by definition, a purposeful IT artifact created to address an important organizational problem." [18, pp. 82]. Later in the paper [18, pp. 87] they describe results as input to scientific knowledge base and this does not add much to the four defined outcomes (as mentioned above). They only add new/improved evaluation methods.

It is interesting to compare their description with a well-established definition of action research (another change oriented research approach). "Action research aims to contribute both to the practical concerns of people in an immediate problematic situation and to the goals of social science by joint collaboration within a mutually acceptable ethical framework" [29]. In this classical definition there is an explicit reference to two goals; practical and scientific goals. These two combined goals have been seen as a key characteristic of action research by several other scholars as well; e.g. [24]. We think that a proper definition of design research should include a reference to two such goals in a similar way. It could be formulated something like this: Design research aims to contribute 1) through designs as solutions to practical problems and needs of people and 2) also to the knowledge goals of a scientific community. 
In our review of March \& Smith [23] and Hevner et al [18] - in section 1 above we introduced the notions of abstract vs. situational knowledge. We will use this knowledge pair in order to clarify both results and activities of design research. The purpose of abstract knowledge is to create an understanding of phenomena and be a basis for use in different (practical) situations. Abstract knowledge is generalized knowledge where specific situational properties are disregarded (abstracted away from). As said above, a systems development method is a good example of such abstract knowledge. Its aim is to be used in different development instances. Abstract knowledge is type-knowledge and situational knowledge is specific knowledge in instances. There is a knowledge flow between these two knowledge levels. Situational knowledge may be generalized and abstracted and thus become abstract knowledge. On the other side, abstract knowledge may be applied in situational instances and in such cases this might involve situational adaptation and modification of the abstract knowledge.

Design research produces different artefacts. Artefacts can be IT systems (software applications) but also other types of "meta artefacts" as constructs, methods and models [16]. Design research uses and produces design knowledge. It uses abstract design knowledge and it produces abstract as well as situational design knowledge. If it did not produce any abstract knowledge, then it would not be any scientific activity; it would only be plain design. Following this knowledge differentiation we divide design research into two activity layers: 1) design practice that produces situational design knowledge and concrete artefacts and 2) meta-design that produces abstract design knowledge. Meta-design can be seen as 1) a preparatory activity before situational design is started and 2) a continual activity partially integrated with the design practice 3 ) a concluding theoretical activity summarizing, evaluating and abstracting results directed for target groups outside the studied design and use practices. We chose the concept 'meta-design' although it also involves classical scientific activities like data analysis, evaluation and theorizing. We have depicted these activity layers in figure 1. As all models this is a simplification. It does not describe the important influences from communities/situations to design research/design practices.

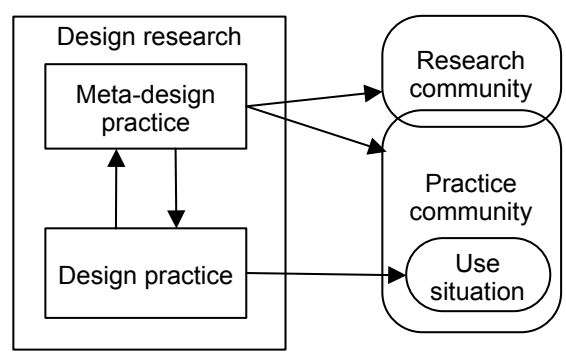

Fig. 1. Design research as meta-design and design practice serving communities and situations

In section 1 above, when inspecting the four outcomes described by March \& Smith [23] and Hevner et al [18], we made a provisional classification of constructs and methods into abstract design knowledge and models and instantiations as situational knowledge/results. This was done from a close reading of $[18,23]$. These 
types of results can however be expanded using the abstract - situational dichotomy; cf. table 1 . Constructs do not only need to be abstract; there might also be situational constructs. These should be concepts that are specific in the design situation. Following Hevner et al [18] models are conceived as situational (cf. analysis and quotes in section 1 above). This is, however, a too restricted view on models. We can use one example to illustrate; the Action Workflow Loop [25]. This is a generic action pattern consisting of four action phases. Based on this generic model (functioning as a template) it is possible, in situational design to create situational models (loop models) consisting of these four action phases. We should therefore distinguish between generic models (as abstract design knowledge) and situational models (as situational design knowledge).

Table 1. Different outcomes differentiated into abstract vs. situational

\begin{tabular}{|l|l|l|}
\hline $\begin{array}{l}\text { Activity type } \\
\text { Outcome }\end{array}$ & $\begin{array}{l}\text { From meta-design: } \\
\text { Abstract design knowledge }\end{array}$ & $\begin{array}{l}\text { From design practice: } \\
\text { Situational design knowledge } \\
\text { and results }\end{array}$ \\
\hline Constructs & Abstract concepts & $\begin{array}{l}\text { Situational concepts (may be } \\
\text { applied and adapted from abstract } \\
\text { concepts) }\end{array}$ \\
\hline Models & Generic models & Situational models \\
\hline Methods & Guidelines for design practice & $\begin{array}{l}\text { Parts of a situational system or } \\
\text { process }\end{array}$ \\
\hline Instantiations & $\begin{array}{l}\text { (System abstraction with key } \\
\text { properties) }\end{array}$ & $\begin{array}{l}\text { IT systems } \\
\text { (prototype or working system) }\end{array}$ \\
\hline
\end{tabular}

Following March \& Smith [23] we classify methods as abstract design knowledge. Situational design can of course involve a design of a set of steps to perform a task within a system or related to a system. This means that situational design practice can involve design of situational methods.

Instantiations are not conceived as knowledge in the same way as constructs, models and methods. These three outcomes are inter-subjective knowledge usually expressed in texts or other symbols. We understand instantiation to be the key designed object and as such (in DR/IS) mainly an IT system (a software application). It can be a prototype/part of a system or a working system. IT systems are not knowledge per se, they are expressions and manifestations of knowledge. During the design of such systems, situational design knowledge may be expressed as vehicles for design. We conceive such expressed design knowledge (as descriptions/ specifications of systems) mainly to be in the form of situational models.

This conceptual expansion is summarized in table 1. Since March \& Smith [23] and Hevner et al [18] do not use the knowledge pair abstract and situational design knowledge, we do not know whether our conceptual expansion is fully in line with their view on outcomes from design research. What is presented here should however be seen as a refinement of their framework. 
This analysis is also partially in line with Sjöström \& Ågerfalk [32] who have constructed a design research framework consisting of three polarities: "design v. research, product v. process, and abstract v. concrete". We use the terms abstract vs. situational instead. We do not use the terminology "design v. research" since design practice is an empirical part of research. Our distinction is meta-design vs. design practice. From our analysis it is also possible to clarify the differences between design practice as part of design research and design practice besides design research. To count as part of DR, design practice needs to be performed as an integral constituent of a research endeavour and it should be explicitly instrumental in relation to this scientific purpose of creating abstract and valid knowledge. Normal design practice is performed with no purpose of contributing to research and abstract research-based knowledge. Such normal design practice can of course apply abstract design knowledge (from scientific knowledge base) in design processes, but such knowledge application does not make it research in itself.

It is also important to state what the proper research outcomes from design research are. We make a distinction between research end results and intermediary results (within the research process). All examples of situational design outcomes are seen as intermediary results, also the instantiated IT artefact! These outcomes are, in a research perspective, to be seen as empirical data. These data are used for hypothesis testing, evaluation and theorizing into abstract knowledge. Our claim is that abstract design knowledge should be seen as the research end results from design research. A designed IT system is just an intermediary result in the same way as observations and other types of empirical data, as well as triggers for data (as hypotheses, interview questions, observation protocols) are intermediary results in the research process. This means that design practice (within design research) is to be seen as an exploratory empirical part of this research.

An IT system may be a deliverable from a design research endeavour to a user community. In that sense, it can be seen as a kind of end result - as something separate leaving the design research process. It is however not seen as a research knowledge end result, since it is not conceived as knowledge (it is a manifestation of knowledge) and it is a situational result (not an abstracted one). Practice/research communities can of course be interested in IT systems (from design research). They can study them in the same way as they can study other examples/illustrations (as data) from inquiries. Instantiations are exemplars, not abstract knowledge results.

We claim that the purpose of information systems as a science is to create valid abstract knowledge. This is mainly done through empirical and conceptual development. Empirical studies of diverse kinds play decisive roles for the creation of a scientific body of knowledge. Exploratory studies involving design practices contribute with powerful empirical data for developing and testing abstract design knowledge.

\section{The Multi-grounding Perspective}

Design theories and other design knowledge need to be justified. Goldkuhl [12] distinguishes between three ways to justify such design knowledge. There are three types of knowledge sources for justification: 
- Empirical observations

- Other knowledge of theoretical character

- The design knowledge itself

The justification of design knowledge means to investigate and present warrants for such knowledge. The three types of knowledge sources and warrants give rise to three grounding processes: Empirical grounding, theoretical grounding and internal grounding (figure 2). Empirical grounding comprises grounding through application of design knowledge and observations of its utilisation and effects. The use of external theories can be a grounding of prescriptive design knowledge in explanatory kernel theories [12, 19]. Theoretical grounding includes also grounding in concepts and values. Internal grounding involves control of internal cohesion and consistency. Goldkuhl [12] argues that all three grounding processes should be applied. These three types of knowledge sources are used both for generation and justification of design knowledge. A design theory may be partially derived from and inspired by other theories and through empirical observations.

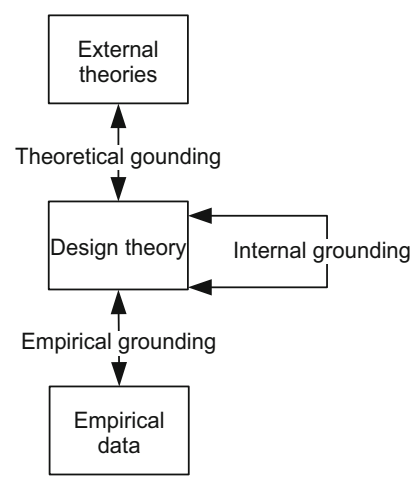

Fig. 2. Three types of grounding [12]

The development of design theory/design knowledge will be an emergent process with continually shifting focus between generation and validation and between the three types of knowledge sources (empirical data, other theories, the design theory itself). Examples of multi-grounding processes are given in $[1,9,12,21]$.

\section{Two Design Research Cases}

\subsection{The Case of e-Me as a Design Research Endeavor}

This case of e-Me is driven from a desire to make a contribution the situation of citizens' challenges of coping with a rapidly increasing number of sites and e-Services. Citizens are continually being exposed with numerous web-sites of different offerings and a challenge quest is to remember and cope with a multitude of user IDs, passwords and login procedures. Many citizens have several email accounts. Consequently a lot of time is spent on logging on to different e-mail systems, trying to find 
passwords and links to various sites. Sometimes e-services are not used, because it's easier to do it the "traditional" way than to figure out the electronic.

In the e-Me Project, a radical approach to this, is to issue the citizen with an electronic assistant, an e-Me, that providers of e-services are required to address with when interacting with the citizen [4]. It might be thought of as turning the internet around. Rather than having citizens find and keep track of sites, the sites will have to come to the citizen and interact with them in the way specified by them. This concept is to see as a counter reaction to the massive onslaught of sites, home pages and email spam. There is nothing inherent in the internet technologies that makes the internet necessarily organization centric. The e-Me concept clearly illustrates how the same technologies can be used to increase the initiative of the citizens.

This design research endeavour suited perfectly to both utilize the development and exploration of the role of an e-Me for coping with these problems (situational knowledge) and to develop valid abstract knowledge. The development of the abstract knowledge was to be seen as a contribution to an ongoing dialogue of how to utilize co-design in multi-stakeholder settings. The notion of co-design is inspired by Churchmann [8] and has then been brought into the IS-community by e.g. Forsgren [11] by the development of a first co-design framework. This framework is a multistakeholder model in which all stakeholders concerns, related to a certain co-design situation, are taken into consideration by either inviting, or considering perspectives of, diverse stakeholders.

In the project, a choice was made to use students as one category of citizens. Early in the project a design vision was formulated that expressed that "the students should not need to go to the information - the information rather comes to the students based on the active profile set by the student." [20]. This design research had thus two missions:

- To contribute to the development of co-design as philosophy and method for stakeholder-driven business development (desired abstracted design knowledge)

- To contribute to the understanding of the next generation of internet-based services through the exploration of the role of an e-Me in a practical context (situational design knowledge)

The project (2005-2007) was organized in three phases; Concept development, prototype realization, and proof-of-concept. Each of the phases involved students as codesigners and resulted in both situational design knowledge as well as abstract design knowledge.

In the concept development a number of co-design workshops were conducted as ideal-oriented design studies engaging numerous (future) users and service providers resulting in eight different scenarios documented with text and cartoons as two types of models [3]. The situational design knowledge was a validated description of an ideal future with e-Me as an integrated part of the life situation. In the development of abstract design knowledge, founded in (soft) systems theory, experiences from conducting these co-design workshops were used as a basis resulting in co-design as an approach to border-crossing, network innovation [5].

In the prototype realization the results from the concept development was used as an input. In this phase a number of micro scenarios were derived from the co-design scenarios described. These micro scenarios (models) were used for the system developers to design and build a pilot version of the e-Me - an instantiation of e-Me in 
software (IT-artefact) as situational design result. A small group of users were involved in test and evaluation during this phase. This design practice resulted in abstracted design knowledge related to approaches to converting scenarios to software requirements, close user interaction integrated in the development process, and the role of systems development in a design research setting.

In the phase of proof-of-concept the first prototype of e-Me was deployed for a group of 120 people who became a part of the e-Me project group and co-designers. The students co-designed e-Me by trying out the prototype - both in order to identify shortcomings in the application and identify new situations, both within and beyond the school setting, when an e-Me would be of assistance. In design practice terms the e-Me became the IT-artefact that gave rise to use effects. These use effects also resolved in an increased understanding of the students' desires of IT-services related to their life situation. Founded in approaches to participatory design [26] as well as language/action approaches to communication modeling [25] an approach for integrated development, use, and learning in a co-design setting [22] as abstract design knowledge was put forward.

To summarize the essential characteristics from the e-Me project as a design research endeavour, this project has both resulted in an overall goal of designing and evaluating an e-Me artefact (on the situational level) and a multi-grounded emergent (co-)design theory (on the meta-design level).

\subsection{The Case of BITA as a Design Research Endeavor}

BITA is an e-government project [13, 33]. The area for development is personal assistance for disabled persons. In Sweden there are two legal acts (and several other statutes) governing this kind of public support. These acts regulate who can apply for personal assistance, how to apply, how to organise and deliver these services and the financing of these services. This egov project concerning allowances for personal assistance was started due to the very cumbersome administration and needs for better quality in time and cost accounting. The two legal acts have given rise to fairly complicated work processes and interaction patterns between different stakeholders. In the project group there were representatives both from several municipalities (responsible for the delivery of the personal assistance services) and from the Social Insurance Agency (responsible for authority decisions and financing). Two researchers participated actively in the project; making it an action research and design research endeavour.

The project started with a workpractice diagnosis and process analysis. New interorganisational processes were designed and proposed. These proposals included also new IT solutions for time and cost accounting. In order to avoid much of the cumbersome paper work, the project group suggested that the signatures on invoices from municipalities to the Social Insurance Agency should be replaced by an IT system built on the idea of "social transparency" [33]. The system should comprise time information (concerning personal assistance services) of diverse types; scheduled time, reported time (through mobile media), determined time (by the managers) together with commentaries from the concerned stakeholders (the clients, their fiduciaries, the personal assistants, the managers). This was not just a loose design idea. It was operationalised and implemented first in prototypes and later in the system to run. 
This made it possible for different stakeholders to judge and evaluate the idea and thereby for the researchers/designers to continually revise and refine the design.

This principle for social transparency was derived from a design theory that was actively used during the IS design: the IS actability theory [2, 14]. In this design theory there is one design criterion, "actor visibility", that was a key inspiration for the emergence of the design ideal of social transparency. This emergent concept has later been analysed and abstracted and fed back to the actability theory [33]. This means both a kind of further empirical grounding as well as a theoretical refinement. The emergence of the social transparency idea did not only come from theory. To a large degree, this was an innovative response to the experienced practical problems and the high ambitions to reduce costs and lead time for administrative work.

However, this idea of a new IT system to replace signatures from clients was not accepted by the Social Insurance Agency with reference to authority statutes. A conflict emerged between this agency and the project group. There were different legal interpretations made by different stakeholders. This led to an in-depth analysis of different legal pre-conditions for this egov initiative. A key notion emerged during this analysis: value balancing [13]. There may be different legal constraints in an egov development project. The way forward is not only to study regulations that may comprise rules which could hinder the proposed development. It is necessary to study regulations of different kinds (domain-specific regulations, general administrative regulations, egov policies) and on different levels (laws, ministry regulations, authority regulations, policy documents). The value balancing should identify values behind the regulations and give priorities to basic values [13]. Due to these conflicting legal interpretations in this egov initiative, the value balancing emerged as an important activity which later also was theorised [13]. This can be seen as an embryonic design theory for handling legal barriers in egov development. The idea of value balancing was later theoretically grounded in institutional theory [30].

\section{Multi-Grounded Design Research}

Based on the conceptual analyses (in sections 1-3 above) and the two empirical design cases (in section 4) we present a model for multi-grounded design research (MGDR).

Design research consists of an empirical part (a design practice) and a theoretical part (meta-design). There is a continual interaction between design practice and metadesign (figure 1). The two parts exchange knowledge. Meta-design produces abstract design knowledge and the design practice produces situational design knowledge and other situational results (instantiations/IT systems). These knowledge types and results are exchanged between the two parts of design research. The knowledge exchanges are also parts in grounding processes. Situational design knowledge is used for empirical grounding of abstract design knowledge and abstract design knowledge is used for theoretical grounding of situational results. This will be further explicated below.

Goldkuhl [12] presented a model for multi-grounding of design theories; cf. section 3 above. In this paper we mainly use the notion of abstract design knowledge instead of design theory. We conceive abstract design knowledge to be a broader notion, encompassing design theory and possibly also other knowledge types than those 
within a design theory. There are still controversies concerning what to include in and how to divide a design theory $[15,35,36]$. We would like to add that we are not in opposition against the notion of design theory. We do find it fruitful, but there would be another paper to resolve issues concerning constituents of design theories.

Instead of talking about design theory and its multi-grounding through theoretical, empirical and internal grounding (as in [12]), we would instead talk about multigrounding of abstract design knowledge. We also expand the grounding reasoning to situational design knowledge and results. This is depicted in figure 3 .

We distinguish between the theoretical level (of meta-design) and the practicalempirical level of situational design knowledge and design practice. Following Goldkuhl [12], abstract design knowledge should be grounded 1) empirically (in empirical knowledge), 2) theoretically in other theories (and similar abstract sources) and 3) internally making the abstract design knowledge a coherent whole. In abstract design knowledge we include constructs, methods and generic models (see section 2 above). We also include values [12] and (design) principles, which can be seen as abstractions of methods. A design theory may encompass all these parts (and possibly more) and therefore we add theory to the constituents of abstract design knowledge to have it complete (figure 3 ).

The situational level is centred around situational design knowledge. Design actions produce situational design knowledge. Such knowledge is expressed mainly in situational models (model-artefacts) and the produced IT artefacts (instantiations). The situational design knowledge should be theoretically grounded in the abstract design knowledge. This means that the abstract knowledge (e.g. constructs, values, methods, generic models) informs the design process. It is also so that the situational results are explicitly checked against the abstract knowledge to investigate compliance. It should however not be that theoretical compliance and grounding should a priori be given priority over proposed designs if these designs are found practical. Theories are (in the pragmatic view) always provisional and emergent. New knowledge can be developed through practical design. The produced situational design knowledge should be informed and governed by practical knowledge as for example problems, goals and needs. The proposed design should be a conscious and reflective response to these practical needs: a practical grounding of purpose, relevance and compliance. The proposed designs (models as well as instantiations) should also be evaluated against anticipated and observed use effects: a consequential grounding. These knowledge types (background and projection knowledge) constitute sources for a practical-empirical grounding of situational design knowledge/results.

To this we can add internal grounding. Systems are built from models. There are often several different types of models produced during an IS development and there are well-known model goals as traceability and cohesion. Models and systems should be a coherent whole without too much contradiction. Situational models should be checked that they are sufficiently congruent.

Abstract and situational design knowledge will continually emerge during the design research process. They will inform and influence each other in a dialectic dance. As can be seen from figure 3 , there will be a mutual grounding between these kinds of knowledge. 


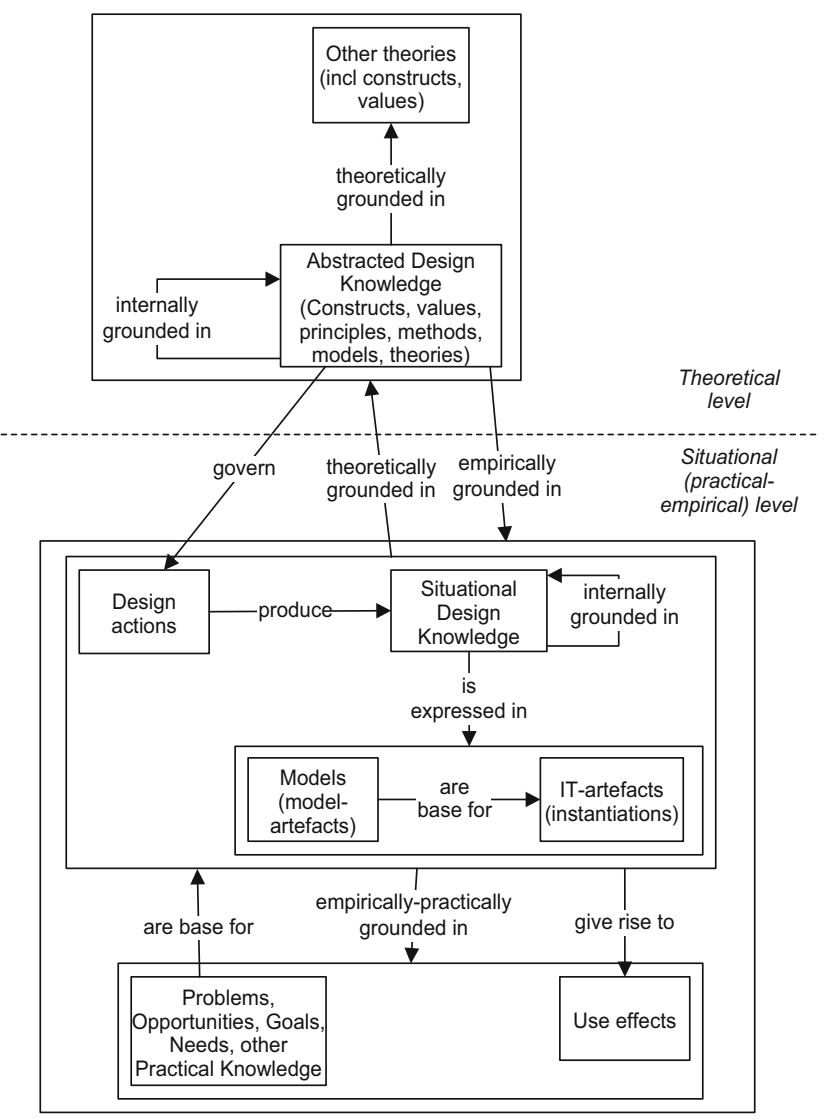

Fig. 3. Multi-grounding of design knowledge

Design practice (in DR) should be theory-informed. This does not necessarily mean that a design theory is first chosen and then used as a test basis in the design practice. The design research can be governed by an interest in some design challenges and available opportunities for practical design work. Such practical design concerns can govern the search for possible abstract design knowledge (can be generic models, prescriptive design theories or methods or even relevant explanatory kernel theories) to be used as a basis for practical design. If no proper theoretical basis is found in the search process, a development of some piece of abstract design knowledge can emerge as a direct response to the practical design needs. This abstract design knowledge can then continually be modified and checked against the emergent situational designs and their use effects.

This means also that research questions and design hypotheses need not be explicitly given at the start of the DR endeavour. They can continually emerge during the DR process when pre-knowledge meets practical design challenges. Some ideas will usually exist in the beginning, but they can be changed during the process if other and more relevant research and design issues are discovered. 


\section{Conclusions}

In the IS-field there is and has been an intense debate related to the application of, and the role of, design research. In this paper some conceptual flaws related to knowledge creation in design research have been acknowledged. Special concern has been the different types of knowledge that could arrive from design research and its implications for knowledge generation and grounding processes.

We have made a distinction between two inter-related practices in design research; the theorising meta-design practice vs. the situational design practice. In design research these two practices produce knowledge and artefacts on two levels; abstracted vs. situational knowledge. In this paper we have distinguished between four types of outcomes (artefacts) which have different meanings related to the two inter-related practices. These four types of outcomes (following [18]), are constructs, models, methods, and instantiations. This means that we acknowledge IT artefacts vs. other types of artefacts as results of design research endeavours.

In knowledge development validity claims for produced knowledge should be raised. To some extent, processes of theoretical grounding by explicating relations to the knowledge base has been advocated by design researchers, but this is too limited. Three types of knowledge sources for justification are therefore acknowledged with appurtenant grounding processes in this paper; empirical grounding, internal grounding, and theoretical grounding. Based on these different knowledge sources, and the distinction between the meta-design practice and the design practice a framework for multi-grounding of design knowledge has been formulated.

Of special concern in design research is the emergence of knowledge through the interplay between the two main activities build and evaluate. However, the multigrounded framework rests upon this, but emphasises also that the design researcher need to be flexible in which way and order abstract design knowledge influence situational design knowledge and vice versa. The implications of this are also that research questions and design hypothesis do not need to be stated at the start of the DR endeavour. They might emerge throughout the DR-process. The same goes for the identification of scientific dialogues in which evolving abstract knowledge become an important contribution to.

In clarifying the two layers of design knowledge we have also touched upon the relation to action research. Both design research cases in this paper included also action research. Future research will, based on this design knowledge dichotomy, try to develop a framework integrating design research and action research.

\section{References}

1. Ågerfalk, P.: Grounding through Operationalization: Constructing Tangible Theory in IS Research. In: Proc of the 12th European Conference on Information Systems (ECIS 2004), Turku (2004)

2. Ågerfalk, P.J.: Investigating Actability Dimensions: A Language/Action Perspective on Criteria for Information Systems Evaluation. Interacting with Computers 16(5), 957-988 (2004) 
3. Albinsson, L., Forsgren, O., Lind, M.: e-Me Stories \& Scenarios - The Ideal Electronic Galaxy of the Student, University College of Borås, Sweden (2006a)

4. Albinsson, L., Lind, M., Forsgren, O., Ozan, H.: Turning the internet around - e-Me: The Students ideal e-Service. In: Cunningham, P., Cunningham, M. (eds.) Exploiting the Knowledge Economy: Issues, Applications, Case Studies. IOS Press, Amsterdam (2006b)

5. Albinsson, L., Lind, M., Forsgren, O.: Co-Design: An approach to border crossing, Network Innovation. In: Cunningham, P., Cunningham, M. (eds.) Expanding the Knowledge Economy: Issues, Applications, Case Studies. IOS Press, Amsterdam (2007)

6. Baskerville, R., Pries-Heje, J.: Grounded action research: a method for understanding IT in practice. Accting. Mgmt. \& Info. Tech. 9, 1-23 (1999)

7. Baskerville, R.: What design science is not. European Journal of Information Systems 17, 441-443 (2008)

8. Churchman, C.W.: The design of inquiring systems. Basic Books, New York (1971)

9. Cronholm, S.: Illustrating Multi-Grounded Theory. In: 3rd European Conference on Research Methodology for Business and Management Studies, Reading (2004)

10. Dewey, J.: Logic, the Theory of Inquiry. H. Holt and Company, New York (1938)

11. Forsgren, O.: Samskapande Datortillämpningar: En systemteoretisk ansats för lösning av vissa förändringsproblem vid administrativ datoranvändning (Doctoral thesis), Umeå universitet (1988)

12. Goldkuhl, G.: Design Theories in Information Systems - A Need for Multi-Grounding. Journal of Information Technology and Application (JITTA) 6(2), 59-72 (2004)

13. Goldkuhl, G.: Innovation in a regulated environment? - Legal barriers for e-government development. International Journal of Public Information Systems 2009(2), 77-95 (2009)

14. Goldkuhl, G.: Pragmatic Qualities of Information Systems - Actability Criteria for Design and Evaluation. Invited paper to the 11th International Conference on Informatics and Semiotics in Organisations (ICISO), Beijing (2009)

15. Gregor, S., Jones, D.: The Anatomy of a Design Theory. Journal of the Association for Information Systems (JAIS) 8(5), Article 2, 312-335 (2007)

16. Iivari, J.: A Paradigmatic Analysis of Information Systems As a Design Science. Scandinavian Journal of Information Systems 19(2), 39-64 (2007)

17. Hevner, A.R.: A Three Cycle View of Design Science Research. Scandinavian Journal of Information Systems 19(2), 87-92 (2007)

18. Hevner, A.R., March, S.T., Park, J., Ram, S.: Design Science in Information Systems Research. MISQ 28, 75-106

19. Kuechler, B., Vaishnavi, V.: On theory development in design science research: anatomy of a research project. European Journal of Information Systems 17, 489-504 (2008)

20. Lind, M., Berglund, S.: e-Me - the students best friend. In: The 14th European University Information Systems Organisation (EUNIS) congress, EUNIS 2008 VISION IT - Visions for IT in Higher Education, University of Aarhus Universitet, Denmark (2008)

21. Lind, M., Goldkuhl, G.: How to develop a Multi-Grounded Theory: The evolution of a business process theory. Australasian Journal of Information Systems (AJIS) 13(2), 68-85 (2006)

22. Lind, M., Rittgen, P.: Challenges of Co-Design: The Case of e-Me. In: Handbook of Research on Socio-Technical Design. Idea Group, Hershey (2009)

23. March, S.T., Smith, G.F.: Design and natural science research on information technology. Decision Support Systems 15, 251-266 (1995)

24. McKay, J., Marshall, P.: The dual imperatives of action research. Information Technology \& People 14(1) (2001) 
25. Medina-Mora, R., Winograd, T., Flores, R., Flores, F.: The Action Workflow Approach to Workflow Management Technology. In: Turner, J., Kraut, R. (eds.) Proceedings of the Conference on Computer-Supported Cooperative Work, CSCW 1992. ACM Press, New York (1992)

26. Mumford, E.: Designing human systems, the ETHICS approach. Manchester Business School, Manchester, UK (1983)

27. Nunamaker, J.F., Minder, C., Purdin, T.D.M.: Systems Development in Information Systems Research. Journal of Management Information Systems I Winter 1990-91 7(3), 89$106(1991)$

28. Pries-Heje, J., Baskerville, R., Venable, J.: Strategies for design science research evaluation. In: Proceedings of the 16th European Conference on Information Systems, Galway, Ireland, pp. 255-266 (2008)

29. Rapoport, R.: Three dilemmas of action research. Human Relations 23, 499-513 (1970)

30. Scott, W.R.: Institutions and organizations. Sage, Thousand Oaks (1995)

31. Simmons, O.E., Gregory, T.A.: Grounded Action: Achieving Optimal and Sustainable Change. Forum Qualitative Social Research (FQS) 4(3) (2003)

32. Sjöström, P.J., Ågerfalk, J.: An Analytic Framework for Design-oriented Research Concepts. In: Proceedings of the Fifteenth Americas Conference on Information Systems, San Francisco, California, August 6-9 (2009)

33. Sjöström, J., Goldkuhl, G.: Socio-instrumental pragmatism in action. In: Whitworth, B., De Moor, A. (eds.) Handbook of Research on Socio-Technical Design and Social Networking Systems. IGI, Hershey (2009)

34. Strauss, A., Corbin, J.: Basics of qualitative research. Techniques and procedures for developing Grounded Theory, 2nd edn. Sage, Newbury Park (1998)

35. Venable, J.: The Role of Theory and Theorising in Design Science Research. In: First International Conference on Design Science Research in Information Systems and Technology, Claremont, California, pp. 1-18 (2006)

36. Walls, J.G., Widmeyer, G.R., El Sawy, O.A.: Building an Information System Design Theory for Vigilant EIS. Information Systems Research 3(1) (1992)

37. Walls, J.G., Widmeyer, G.R., El Sawy, O.A.: Assessing Information System Design Theory in Perspective: How Useful was our 1992 Initial Rendition? Journal of Information Technology Theory and Application (JTTTA) 6(2), 43-58 (2004) 